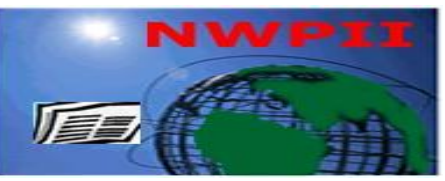

American Journal of Biomedical Sciences

ISSN: 1937-9080

nwpii.com/ajbms

\title{
Characterization of Sperm Immobilization Factor from Escherichia coli and Its Receptor to Study the Underlying Mechanism of Sperm Immobilization
}

\author{
Harpreet Vander, Sonia Gupta, Siftjit Kaur, Kiranjeet Kaur and Vijay Prabha*
}

Department of Microbiology, Panjab University, Chandigarh, India

*Corresponding Author:

Dr. (Mrs) Vijay Prabha

Professor

Department of Microbiology

Panjab University

Chandigarh-160014.

India

Telephone: $91-172-2534140$

Fax: 91-172-2541770

E mail: satishvijay11@yahoo.com

Received:19 April 2012; | Revised:18 September 2012; | Accepted: 28 October 2012

\begin{abstract}
Sperm immobilization factor (SIF) was extracted and purified from Escherichia coli filtrate. Characterization of SIF using Liquid chromatography -mass spectrometry (LC-MS) revealed its sequence similarity to chaperone protein HchA of E. coli O157:H7. Further the effect of SIF on sperm functions such as acrosome reaction was studied and the results showed that SIF $(500 \mu \mathrm{g} / \mathrm{ml})$ significantly inhibits calcium ionophore induced acrosome reaction. SIF was also found to decrease $\mathrm{Mg}^{++}$ATPase activity of spermatozoa from 869.5 (control) to zero at $25 \mu \mathrm{g} / \mathrm{ml}$. The corresponding SIF binding receptor was also isolated and purified. The tryptic peptide analysis of SIF binding receptor by MALDI-TOF (Matrix assisted laser desorption ionization- time of flight) showed its sequence similarity to chain A structure of human apolactoferrin. Further specificity of SIF and SIF binding receptor was studied by calorimetric studies that showed binding constant $(\mathrm{K})$, enthalpy of binding $\left(\Delta \mathrm{H}^{\circ}\right)$, free energy $(\Delta \mathrm{G})$ and entropy $(\Delta \mathrm{S})$ to be $1460 / \mathrm{M}$ and $-11.7 \mathrm{~kJ} / \mathrm{mole},-18.76 \mathrm{~kJ} / \mathrm{mole}$ and $22.77 \mathrm{~J} / \mathrm{moleK}$, respectively.
\end{abstract}

Keywords: Escherichia coli, sperm immobilization factor, spermatozoa, receptor, acrosome reaction.

\section{Introduction}

Infections of the male genitourinary tract represent a significant health care problem and account for almost $15 \%$ of cases of male infertility [1]. The most discussed and tested microorganism concerning male infertility is Escherichia coli. It is also the principal pathogen causing prostatitis and epididymitis [2]. Diemer et al. [3] have reported negative influence of $E$. coli on sperm motility which also manifests as 
damage on sperm morphology. Many research groups have outlined the negative influence of various $E$. coli strains on motility and motility parameters of human spermatozoa in in vitro experiments. Some investigators have suggested that direct interactions between bacteria and human spermatozoa facilitate sperm immobilization, others have reported evidence for soluble spermatotoxic factors $[4,5]$.

On similar grounds we have also reported the immobilization of spermatozoa by soluble factor i.e. sperm immobilization factor (SIF) from $E$. coli filtrate that was isolated, purified and characterized and its effect on various sperm parameters like acrosome reaction and $\mathrm{Mg}^{++}$ ATPase activity was studied. The acrosome reaction is prerequisite for penetration of spermatozoa through zona pellucida and fertilization of the oocyte and is of prognostic value for sperm fertilization capacity [6]. Vivenes et al [7] have shown that the dynein ATPase activity in axoneme containing fractions of human sperm is $\mathrm{Mg}^{++}$dependent. It thus seems possible that SIF might be affecting the $\mathrm{Mg}^{++}$ dependent ATPase leading to inhibitory effect on motility. Hence the effect of SIF on $\mathrm{Mg}^{++}$ ATPase was evaluated. Further an attempt was made to isolate, the corresponding SIF binding receptor. Calorimetric studies of SIF and SIF binding receptor interaction were carried out to understand the underlying mechanism leading to sperm immobilization

\section{Methods}

\subsection{Microorganism}

The bacterial isolate $E$. coli used in the present study was isolated from semen samples of asymptomatic males undergoing semen analysis at Department of Urology, PGIMER, Chandigarh.

\subsection{Spermatozoa from human males}

Semen samples were obtained from males undergoing semen analysis by masturbation into sterile wide-mouth containers. Ejaculates were collected from the Department of Urology, PGIMER, Chandigarh. Samples were allowed to liquefy at room temperature for $30 \mathrm{~min}$. The preparation of washed sperm samples was also done, in which the sperm cell pellet retained after centrifugation at 500rpm for $10 \mathrm{~min}$ was washed twice with sterile phosphate buffer saline PBS (50mM, pH 7.2).

\subsection{Extraction and purification of SIF}

Sperm immobilization factor was isolated and purified from the filtrate of $72 \mathrm{~h}$ old culture of E. coli using column chromatographic techniques and the homogeneity was checked by polyacrylamide gel electrophoresis (PAGE) [8].

\subsection{Characterization of SIF by LC-MS (Liquid chromatography -mass spectrometry)}

Following PAGE, entire gel was rinsed in ultrapure water; band was excised with a clean scalpel and transferred to $1.5 \mathrm{ml}$ tubes having ultra pure water. Gel pieces were then subjected to tryptic digestion in $\sim 5 \mu l$ trypsin solution $(20 \mathrm{ng} / \mu \mathrm{l})$ for $10 \mathrm{~min}$ at room temperature and then were incubated at $37^{\circ} \mathrm{C}$ for $16 \mathrm{~h}$. Peptide extraction was done by adding peptide extraction solution ( $20 \mu 1$ of $1 \%$ TFA) followed by sonication in water bath sonicator for $5 \mathrm{~min}$. 1$5 \mu 1$ of the extracted peptides were used for subsequent MS analysis. LC-MS analysis was done by injecting $6 \mu \mathrm{l}$ solution into LC-MS/MS (Agilent, Palo Alto, CA, USA) instrument. Data was analyzed using Agilent Ion trap Analysis software version 5.2 and proteins were identified by database search against the MASCOT database.

\subsection{Evaluation of acrosomal status of spermatozoa}

The semen sample was washed twice (500rpm, 5min) with human tubal fluid medium (HTFM) containing 1\% human serum albumin (HSA). Sperm concentration was adjusted to $40 \times$ $10 \% \mathrm{ml}$; the sperm suspension was divided into two aliquots (test and control). The test was incubated with equal volumes of SIF for $3 \mathrm{~h}$ at $37^{\circ} \mathrm{C}$ whereas the control was prepared by adding equal volume of PBS (50mM, pH 7.2) under same conditions. After $3 \mathrm{~h}$, spermatozoa from both test and control were either treated with $0.1 \%$ DMSO (spontaneous acrosome reaction) or $10 \mu \mathrm{M}$ calcium ionophore A23187 (induced 
acrosome reaction) for $1 \mathrm{~h}$ at $37^{\circ} \mathrm{C}$. Subsequently, spermatozoa were washed in HTFM without HSA (500rpm, 10min). After further washing with HTFM the pellet was resuspended in $3 \%$ glutaraldehyde and incubated for $20 \mathrm{~min}$ at $37^{\circ} \mathrm{C}$. The pellet was washed and resuspended in 10$50 \mu \mathrm{l}$ HTFM and smeared on to a glass slide and was stained with Bismark brown $(0.8 \%$ in deionized water, $\mathrm{pH} 1.8$ ) for $5 \mathrm{~min}$, washed three times with water and stained with Rose Bengal $(0.8 \%$ in $0.1 \mathrm{M}$ Tris buffer, $\mathrm{pH} 5.6$ ) for $25 \mathrm{~min}$. Spermatozoa were then dehydrated in $50 \%, 70 \%$ and $96 \%$ ethanol and rinsed with water and examined at $1000 \mathrm{X}$ magnification under light microscope.

\subsection{In vitro effect of SIF on sperm $\mathrm{Mg}^{++}$ ATPase activity}

Semen sample was centrifuged at 500rpm for $10 \mathrm{~min}$ and the sperm pellet was suspended in Tris- $\mathrm{HCl}(0.2 \mathrm{M}, \mathrm{pH}$ 7.6). Washed spermatozoa $\left(1 \times 10^{6} / \mathrm{ml}\right)$ were sonicated at $50 \mathrm{~Hz}$ for $10 \mathrm{~min}$ (10 cycles of $30 \mathrm{~s}$ with $1 \mathrm{~min}$ interval) at $4^{\circ} \mathrm{C}$. The reaction mixture for ATPase consisted of $0.2 \mathrm{ml}$ Tris- $\mathrm{HCl}$ buffer (0.2M, $\mathrm{pH} 7.6), 0.2 \mathrm{ml}$ of $\mathrm{MgCl}_{2}$ $(5 \mathrm{mM}), 0.2 \mathrm{ml}$ of ATP $(6 \mathrm{mg} / \mathrm{ml})$ and $0.2 \mathrm{ml}$ of sonicated sperm suspension. Different concentrations of SIF $(6.25,12.5$ and $25 \mu \mathrm{g} / \mathrm{ml})$ were added to the reaction mixture and incubated at $37^{\circ} \mathrm{C}$ for $1 \mathrm{~h}$. The reaction was stopped by adding $1 \mathrm{ml}$ of $10 \%$ cold Trichloroacteic acid (TCA) and then incubated at $4^{\circ} \mathrm{C}$ overnight for protein precipitation. The control tubes contained all the components of the reaction mixture but TCA was added immediately after mixing the components. Inorganic phosphorus (Pi) released after breakdown of ATP was determined according to the method of Boyce et al. [9]. One unit of ATPase is expressed as $\mu \mathrm{g}$ of the Pi released after $1 \mathrm{~h}$ of incubation.

\subsection{Extraction and purification of SIF binding receptor}

The SIF binding receptor was extracted from washed spermatozoa by salt treatment with $\mathrm{NaCl}$ and purified by molecular sieving through sephadex G-200 and DEAE cellulose as per the procedure standardized in our laboratory [10].

\subsection{Characterization of SIF binding receptor by MALDI-TOF}

Processing of protein bands, tryptic digestion and peptide extraction was done in the same way as described earlier for LC-MS of SIF. Sample for MALDI-TOF analysis was prepared using Dried droplet method and MS analysis was carried out using Flex analysis software (v 2.2, BRUKER). Subsequent MS data analysis was carried out using Biotools software (v 2.2, BRUKER) and MASCOT search engine (Matrix Science) against the NCBI database.

\subsection{Calorimetric studies of SIF binding receptor-SIF interaction}

Microreaction calorimeter was used to determine the enthalpy of binding of SIF with the SIF binding receptor in PBS. Each of the calorimetric vials was filled with $1.5 \mathrm{ml}$ of SIF binding receptor $(200 \mu \mathrm{g} / \mathrm{ml})$ in buffer at $37^{\circ} \mathrm{C}$. A $250 \mu \mathrm{l}$ syringe was loaded with the SIF $(500 \mu \mathrm{g} / \mathrm{ml})$. The experiment was conducted using the titration mode of addition of an injection of SIF solution. An initial period of 200s was allowed for baseline measurement with an injection interval of $800 \mathrm{~s}$. The binding constant, $\mathrm{K}$ and enthalpy of binding, $\Delta \mathrm{H}^{\circ}$ were computed by using iterative non-linear least square regression method.

\section{Results}

E. coli causing $100 \%$ immobilization of human spermatozoa was isolated from the ejaculate of males. SIF was isolated and purified from $E$. coli filtrate, as reported earlier [8].

\subsection{Characterization of SIF by LC-MS}

When the purified SIF was subjected to peptide mass fingerprinting using LC-MS, Mascot score histogram showed sequence similarity with chaperone protein HchA Escherichia coli O157:H7 EDL933 (Fig 1).

\subsection{Evaluation of acrosomal status of spermatozoa}

When the effect of SIF $(500 \mu \mathrm{g} / \mathrm{ml})$ on human sperm acrosome was studied under light microscope, two patterns of staining were observed. Red or pink staining of the acrosomal 
region indicated intact acrosomes whereas white, brown or yellowish acrosomes were interpreted as acrosome reacted. The percentages of acrosome reacted spermatozoa in SIF treated samples were comparable to control (DMSO). Calcium ionophore could induce acrosome reaction in majority of spermatozoa, however coincubation of spermatozoa with SIF in HTFM (with 1\% HSA) followed by ionophore challenge failed to produce the same effect (Fig 2). These results point towards the inhibitory effect of SIF on calcium ionophore induced acrosome reaction.

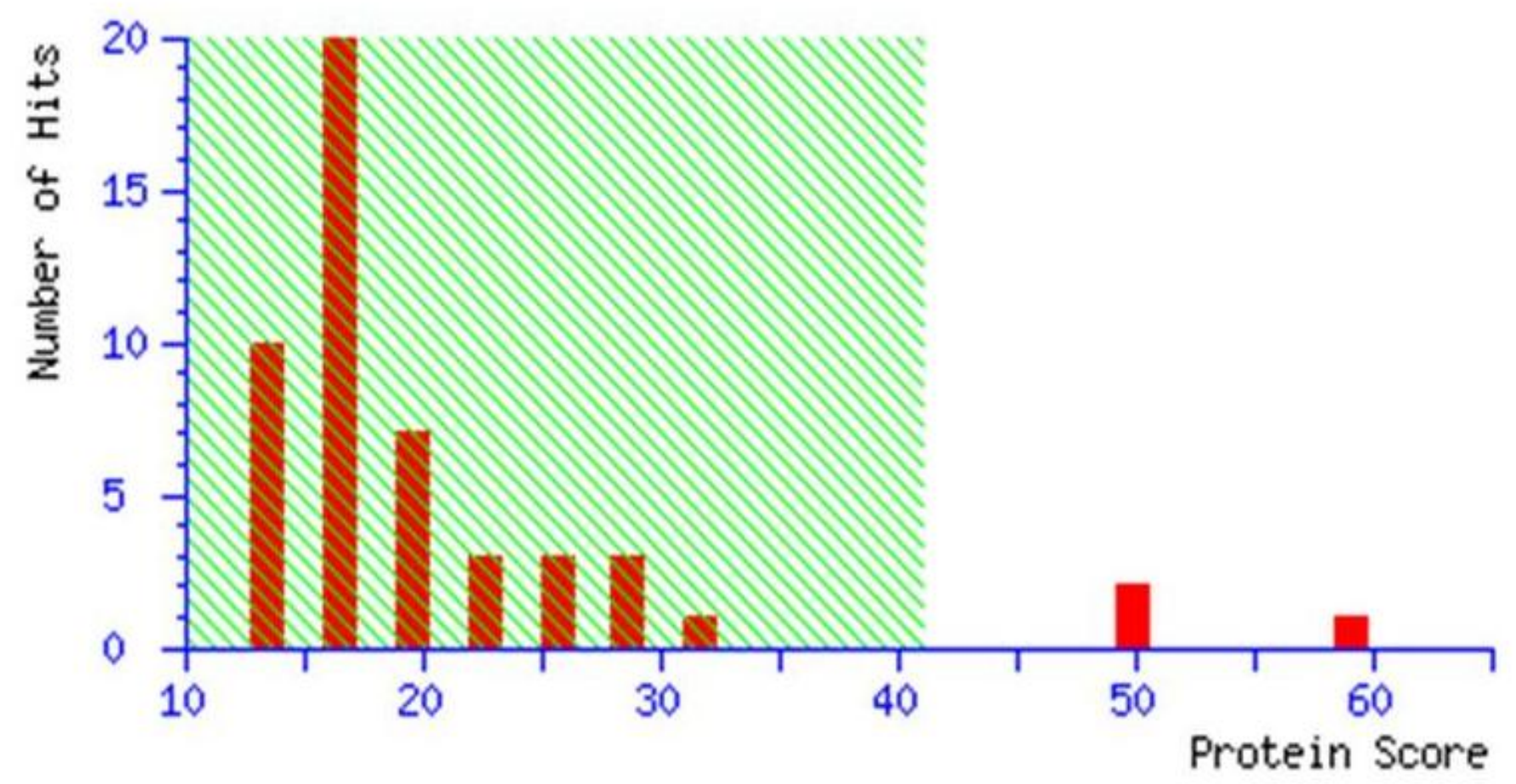

E15802400 Maw: 31259 Scere: 59 Mhthes: 1(1) Sequences: 1(1) emPAT: 0.09

chapeluneputein Hha [Rscherichia coli O157-H7 EDL933]

Figure 1. Mascot score histogram of LC-MS analysis of SIF

Table 1. Effect of SIF on $\mathrm{Mg}^{++}$ATPase activity

\begin{tabular}{|c|c|c|}
\hline S. No. & $\begin{array}{c}\text { Concentration of } \\
\text { SIF }(\boldsymbol{\mu g} / \mathbf{m l})\end{array}$ & $\begin{array}{c}\text { Units of } \\
\text { ATPase }\end{array}$ \\
\hline CONTROL & - & 869.5 \\
\hline 1 & 6.25 & 820.0 \\
\hline 2 & 12.5 & 671.04 \\
\hline 3 & 25 & 0.0 \\
\hline
\end{tabular}

3.3 In vitro effect of SIF on sperm $\mathrm{Mg}^{++}$ ATPase activity

When the effect of SIF on sperm $\mathrm{Mg}^{++}$ ATPase activity was studied the results showed that SIF inhibited $\mathrm{Mg}^{++}$ATPase activity in a dose dependent manner (Table 1). ATPase activity decreased from 869.5 units (control) to zero in presence of $25 \mu \mathrm{g} / \mathrm{ml}$ of SIF. 

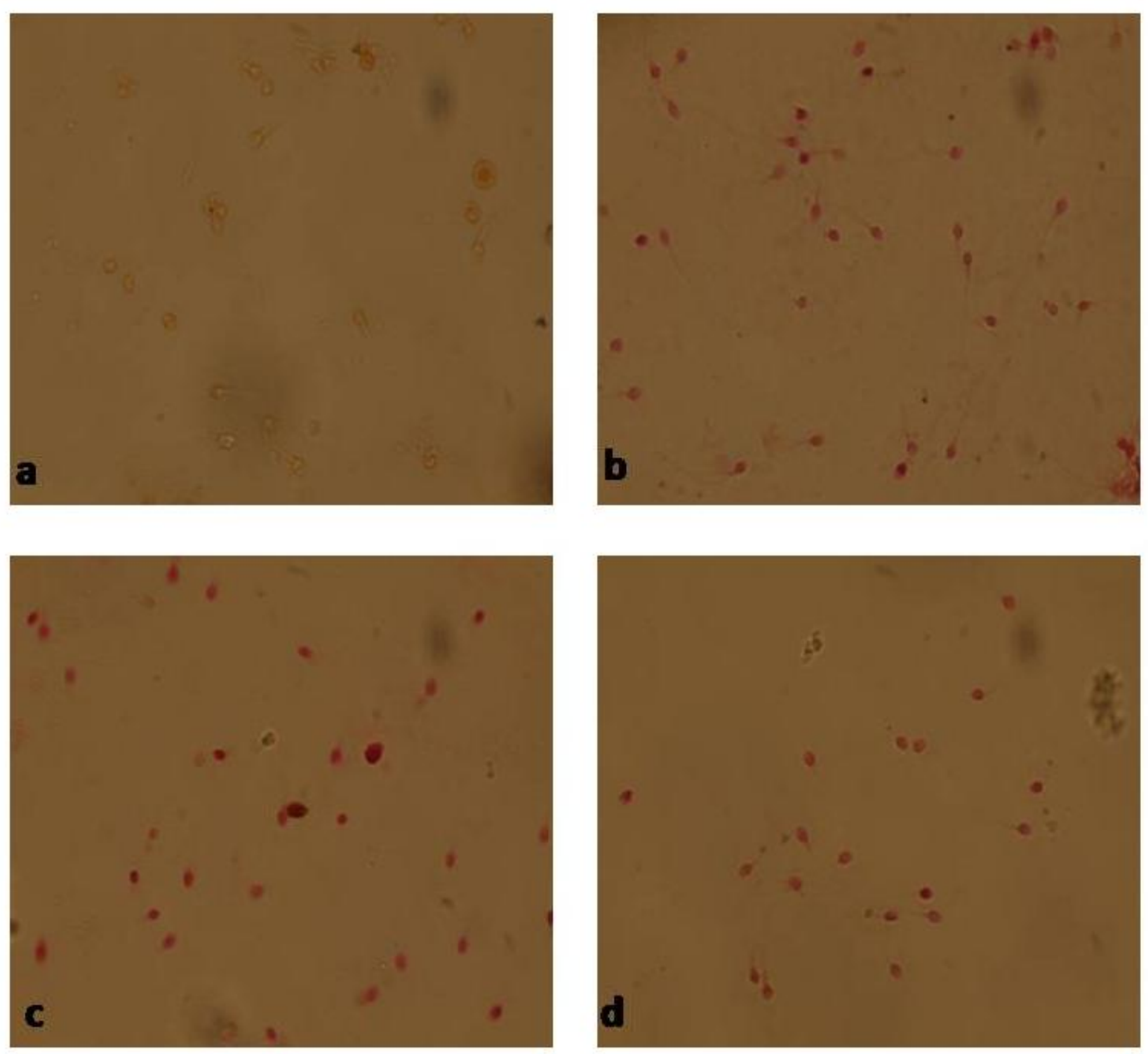

Figure 2. (a) Induced sperm acrosome reaction on treatment with calcium ionophore (1000X)-control, (b) Spontaneous sperm acrosome reaction on treatment with DMSO (1000X)-control, (c) Effect of SIF on calcium ionophore induced sperm acrosome reaction (1000X), (d). Effect of SIF on spontaneous sperm acrosome reaction (1000X)

\subsection{Extraction and purification of SIF binding receptor}

The SIF binding receptor, extracted and purified from spermatozoa had a molecular weight of $113 \mathrm{kDa}$ as reported earlier [10].

\subsection{Characterization of SIF binding receptor by MALDI-TOF}

When the purified SIF binding receptor was subjected to MALDI-TOF, Mascot score histogram showed sequence similarity with Chain A, Structure of Human Apolactoferrin (Fig 3). 


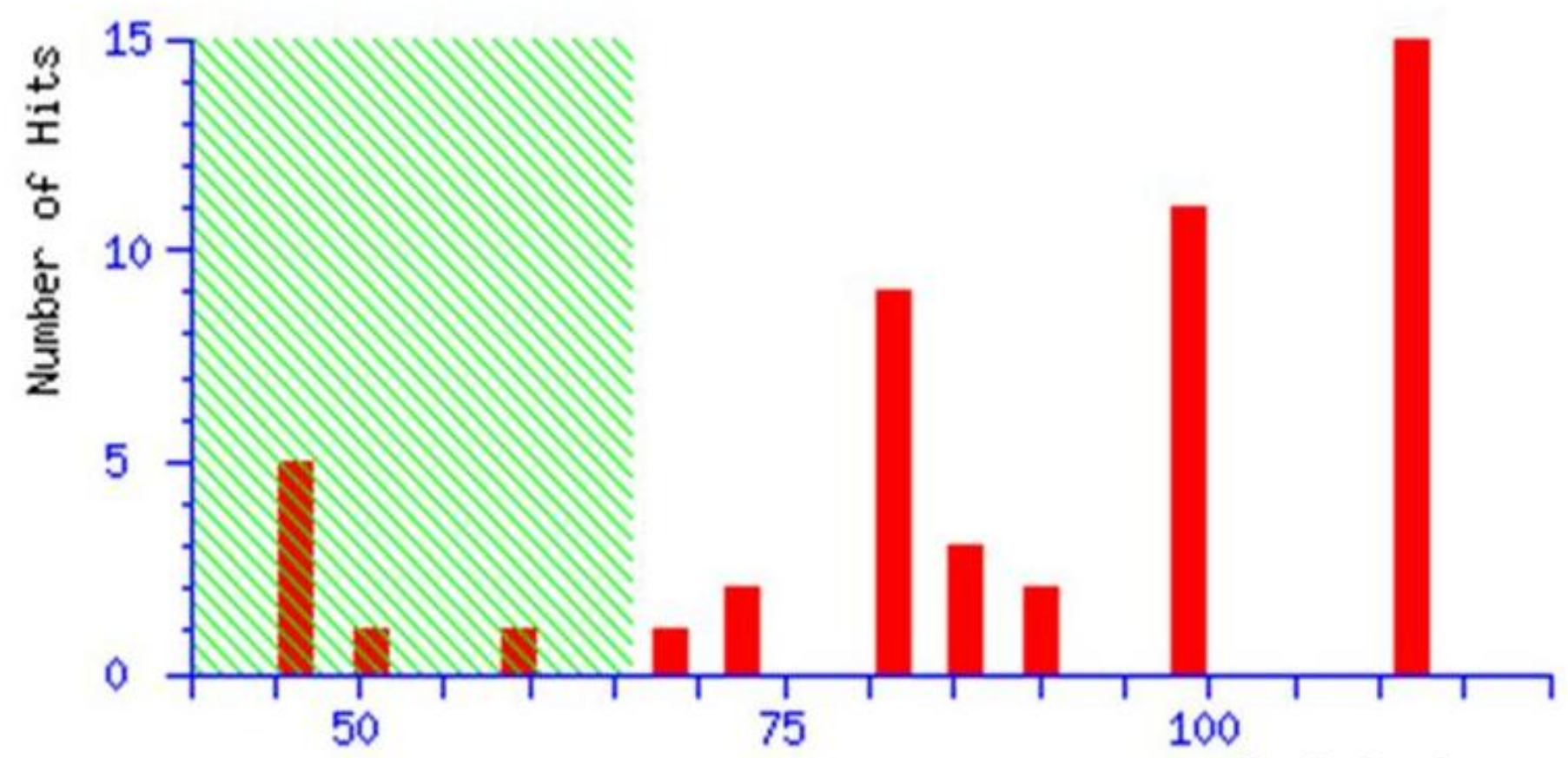

Protein Score

gi/4699853 Hax 77941 Soure: 112 Emedt $15 e-06$ kotchex 15

Chain A, Structure of Hhrman Apolactuferrin At 20 A Resolution.

Figure 3. Mascot score histogram of MALDI-TOF analysis of SIF binding receptor

Table 2. Heat released on SIF binding receptorSIF interaction

\begin{tabular}{|c|c|c|c|}
\hline $\begin{array}{c}\text { S. } \\
\text { No }\end{array}$ & $\begin{array}{c}\boldsymbol{\mu m o l e s} \text { of } \\
\text { SIF }\end{array}$ & $\begin{array}{c}\boldsymbol{\mu m o l e s} \text { of } \\
\text { SIF binding } \\
\text { receptor }\end{array}$ & $\begin{array}{c}\text { Heat } \\
\text { released } \\
(\mathbf{k J})\end{array}$ \\
\hline 1 & $2.67 \times 10^{-4}$ & $2.65 \times 10^{-4}$ & -16.6 \\
\hline 2 & $5.35 \times 10^{-4}$ & $2.65 \times 10^{-4}$ & -10.6 \\
\hline 3 & $8.03 \times 10^{-4}$ & $2.65 \times 10^{-4}$ & -3.7 \\
\hline 4 & $1.07 \times 10^{-4}$ & $2.65 \times 10^{-4}$ & -18.8 \\
\hline
\end{tabular}

\subsection{Calorimetric studies of SIF binding receptor-SIF interaction}

The binding constant, K (1460/M) and enthalpy of binding, $\Delta \mathrm{H}^{\circ}(-11.7 \mathrm{~kJ} / \mathrm{mole})$ were computed from the experimentally calculated enthalpy of interaction between ligand and receptor, using iterative non-linear least square regression method. The values of free energy and entropy were found to be $-18.76 \mathrm{~kJ} /$ mole and 22.77 J/moleK respectively (Table 2 ).

\section{Discussion}

Urogenital infections are considered important factors in male infertility [11]. E. coli probably represents the most frequently isolated microorganism in genitourinary infections [12]. $E$. coli appears to affect different sites of the male reproductive tract and can be accounted for upto $90 \%$ cases of infections. E. coli is isolated frequently from seminal and prostatic fluids in patients with prostatitis and epididymitis [13]. Presumed mechanisms of infertility are the 
following: (a) bacterial attachment to sperm; (b) an immobilizing factor produced by some bacteria; (c) immune system recruitment, and (d) alteration of glandular function.

Earlier Paulson and Polakoski [4] isolated SIF from $E$. coli culture filtrates. The factor was dialyzable, heat stable and spermatotoxic.

On similar grounds, SIF produced extracellularly by $E$. coli has been isolated and purified in our laboratory also [8]. However the factor isolated in our laboratory was heat labile and non-dialyzable. Further the characterization of SIF was carried out. Mass spectrometry has become the method of choice for the rapid identification of proteins and characterization of post translational modifications. Therefore, we chose peptide mass fingerprinting using LC-MS for characterization of SIF. When SIF was compared with peptides and proteins in NCBInr database, the protein HchA chaperon was identified. Many molecular chaperones described so far are members of the hsp60 and hsp70 families. The expression of heat shock protein, hsp 70 was investigated in endometrial samples from patients with unexplained infertility. A significant over-expression of hsp70 was found in the infertile groups, suggesting that a stress response may be involved in the aetiology of unexplained infertility [14].

The acrosome reaction is an exocytotic process that occurs when spermatozoa bind to the zona pellucida and must take place before the spermatozoon can penetrate and fuse with the oocyte. Calcium influx is believed to be an initiating event in the normal acrosome reaction. Inducing calcium influx by using a calcium ionophore is one way of testing the competence of capacitated spermatozoa to undergo the acrosome reaction [15]. It has been reported that results of ionophore-induced acrosome reaction may predict sperm fertilizing ability in vitro. In the present study, the results revealed that SIF could block the ionophore induced acrosome reaction of human spermatozoa. In one of the similar reports by Aitken et al. [16], it was shown that frequent characteristic of patients exhibiting defective sperm function is that their spermatozoa develop refractoriness to calcium signals, such that sperm-oocyte fusion will not occur in the presence of the ionophore A23187. Some investigators have also reported synthetic trypsin inhibitors, known to inhibit variety of trypsin like enzymes including acrosin that have been found to inhibit acrosome reaction in vitro. This supports the fact that SIF could induce such changes which prevents acrosome reaction of spermatozoa.

Motility is strong predictor of sperm fertilization capacity [17]. The energy for this motility is provided by ATP synthesized either by glycolysis in cytoplasm or through oxidative phosphorylation in mitochondria. Spermatozoa possess a large amount of ATPase activity, and several species of the enzyme have been identified such as $\mathrm{Na}^{+}, \mathrm{K}^{+}, \mathrm{Mg}^{++}$dependent transport ATPase, mitochondrial and axonemal ATPases. These cation dependent ATPases account for the breakdown of ATP to release energy for flagellar contractile processes. When the in vitro effect of SIF was studied on human spermatozoa, it was observed that purified SIF at a concentration of $25 \mu \mathrm{g} / \mathrm{ml}$ could completely inhibit the $\mathrm{Mg}^{++}$ATPase activity of spermatozoa. Thus inhibition of $\mathrm{Mg}^{++}$dependent ATPase could be one of the possible mechanisms of sperm immobilization by SIF. In an earlier study by Bouchard and Biswas, [18] it was reported that intact spermatozoa from rat cauda epididymis possess an $\mathrm{Mg}^{++}$dependent ATPase activity that hydrolyse externally added $[\gamma-32 \mathrm{P}]$ ATP. The activity of this enzyme was strongly inhibited $(\sim 85 \%)$ by p-chloro mercuri benzene- sulphonic acid $(50 \mu \mathrm{M})$ or the diazonium salt of sulphanilic acid $(50 \mu \mathrm{M})$.

Further, when characterization of SIF binding receptor was carried out by Matrix assisted laser desorption ionization/time of flight high resolution tandem mass spectrophotometer, the results showed the SIF binding receptor had sequence similarity with A chain of human apolactoferrin. Apolactoferrin is iron depleted form of lactoferrin. Lactoferrin is an iron-binding protein. It is present in semen as a surface antigen on spermatozoa. Hekman and Rumke [19] have shown that one of the antigenic components in human seminal plasma has immunological properties in common with lactoferrin. Further, they showed that it was 
present on seminal spermatozoa, but absent from testis, epididymal extract and testicular spermatozoa.

Receptor ligand interaction is one of the most important molecular processes in biology and is accompanied by change in heat or enthalpy. Calorimeter is an ideal instrument to measure these thermodynamic parameters. These studies offer the direct determination of a complete thermodynamic profile of an interaction, including the free energy, the enthalpy, the entropy, and Gibb's free energy of various biomolecular processes like receptor ligand interaction at reasonable concentrations. In present study, we used these calorimetric methods to study interaction of SIF with purified SIF binding receptor and it was observed that binding of SIF binding receptor to SIF is enthalpically $(-11.7 \mathrm{~kJ} / \mathrm{mole})$ as well as entropically (22.77 J/mole.K) favoured resulting in the Gibb's free energy of $-18.76 \mathrm{~kJ} /$ mole and the binding constant for this interaction was found to be 1460/M.

From the results, it can be concluded that receptor ligand interaction could be responsible for immobilization of spermatozoa by SIF.

\section{Acknowledgements}

The authors would like to thank Dr. S. K. Singh, Department of Urology PGIMER Chandigarh, India, Prof. Renu Chadha, University Institute of Pharmaceutical Sciences, Panjab University, Chandigarh, India and The Centre for Genomic Applications (TCGA), New Delhi, India for their assistance with the experiments described in this report.

\section{References}

1. Diemer, T.; Desjardins, C. Developmental and genetic disorders in spermatogenesis, Human Reproduction, 1999, 5, 120-140. doi: 10.1093/humupd/5.2.120

2. Diemer, T.; Weidner, W.; Michelmann, H.W.; Schiefer, H.G.; Rovan, E.; Mayer, F. Influence of Escherichia coli on motility parameters of human spermatozoa in vitro,
Journal of Andrology, 1996, 19, 271-277. DOI: 10.1111/j.1365-2605.1996.tb00475.x

3. Diemer, T.; Huwe, P.; Michelmann, H.W.; Mayer, F.; Schiefer, H.G.; Weidner, W. Escherichia coli-induced alterations of human spermatozoa. An electron microscopy analysis, International Journal of Andrology, 2000a, 23, 178-186.

4. Teague, N. S.; Boyarsky, S.; Gleen, J.F. Interference of human spermatozoa motility by Escherichia coli, Fertility Sterility, 1971, 22, 281-282.

5. Paulson, J.D.; Polakoski, K.L. Isolation of a spermatozoal immobilization factor from Escherichia coli filtrates, Fertility Sterility, 1977, 28, 182-185.

6. Kohn, F.M.; Erdmann, I.; Oeda, T.; El Mulla K.F.; Schiefer H.G.; Schill, W.B. Influence of urogenital infections on sperm functions, Andrologia, 1998, 30, 73-80. DOI: 10.1111/j.1439-0272.1998.tb02829.x

7. Vivenes, C.Y.; Peralta- Arias, R.D.; Camejo, M.I.; Guerro, K.; Fernandez, V.H.; Pinero, S.; Proverbio, T.; Proverbio, F.; Marin, R. Biochemical identification of dyeninATPase activity in human sperm, Zeitschrift fur Naturforschung, 2009, 64, 747-753.

8. Prabha, V.; Sandhu, R.; Kaur, S.; Kaur, K.; Sarwal, A.; Mavuduru, R.S.; Singh, S.K. Mechanism of sperm immobilization by Escherichia coli, Advances in Urology, 2010; 1-6 doi:10.1155/2010/240268.

9. Boyce A.; Casey, A.; Walsh, G.A. A phytase enzyme based biochemistry practical particularly suited to students undertaking courses in biotechnology and environmental sciences, Biochemistry and Molecular Biology Education, 2004, 32, 336-340.

10. Kumar, V.; Prabha, V.; Kaur, S.; Kaur, K.; Singh, S.K. Receptor dependent immobilization of spermatozoa by sperm immobilization factor isolated from Escherichia coli: Proof of evidence, International Journal of Urology, 2011, 18, 597-603.DOI:10.1111/j.1442-

2042.2011.02784.x

11. Diemer, T.; Huwe, P.; Ludwig, M.; Schroeder-Printzen, I.; Michelmann, H.W.; Schiefer, H.G.; Weidner, W. Influence of 
autogenous leucocytes and Escherichia coli on sperm motility parameters in vitro, Andrologia 2003, 35, 100-105. DOI: 10.1046/j.1439-0272.2003.00523.X

12. Liu, J.H.; Li, H.Y.; Cao, Z.G.; Duan, Y.F.; Li, Y.; Ye, Z.Q. Influence of several uropathogenic microorganisms on human sperm motility parameters in vitro, Journal of Andrology, 2002, 4, 179-182.

13. Weidner, W.; Krause, W.; Ludwig, M. Relevance of male accessory gland infection for subsequent fertility with special focus on prostatitis, Human Reproduction, 1999, 5, 421-432. doi: 10.1093/humupd/5.5.421

14. Nip, M.M.C.; Miller, D.; Taylor, P.V.; Gannon, M.J.; Hancock, K.W. Infertility: Expression of heat shock protein $70 \mathrm{kDa}$ in human endometrium of normal and infertile women, Human Reproduction, 1994, 9, 1253-1256. DOI:cgi/content/short/9/7/1253

15. Liu, D.Y.; Baker, H.W.G. Protein kinase C plays an important role in the human zona pellucida-induced acrosome reaction,
Molecular Human Reproduction, 1995, 3, 1037-1043. doi: 10.1093/molehr/3.12.1037

16. Aitken, R.J.; Harkiss, D.; Buckingham, D. Relationship between iron-catalysed lipid peroxidation potential and human sperm function, Journal of Reproduction and Fertility, 1999, 98, 257-265.

17. Donnelly, E.T.; Lewis, S.E.M.; McNally, J.; Thompson, W. In vitro fertilization and pregnancy rates: the influence of sperm motility and morphology on IVF outcome. Fertility Sterility, 1998, 70, 305-314.

18. Bouchard, G.C.; Biswas, R. Evidence for the occurrence of an ecto-(Adenosine Triphosphatase) in rat epididymal Spermatozoa, Biochemical Journal, 1979, 183, 737-743.

19. Hekman, A.; Rumke, P.; The antigens of human seminal plasma, Proteins Biological Fluids, 1968, 16, 549-552. 